\title{
Computer Documentation for Senior Citizens
}

\author{
Scott Tilley \\ Department of Computer Sciences \\ Florida Institute of Technology \\ stilley@cs.fit.edu
}

\begin{abstract}
The fastest growing market segment of new computer users is senior citizens. For many seniors, the computer is a puzzling device whose inner workings will forever remain a mystery. A lack of understanding of how a computer works doesn't necessarily mean that seniors' interest in using a computer is diminished. But it does mean that most of the documentation written to help them learn computing skills and use common applications is inappropriate. Based on a series of free seminars conducted in the first half of 2003, three issues were identified as key requirements of computer documentation for seniors that addresses their unique circumstances: basic vocabulary, just enough explanation, and exception-oriented guidelines.
\end{abstract}

\section{Categories and Subject Descriptors}

D.2.7 [Software Engineering]: Distribution, Maintenance, and Enhancement - documentation.

K.4.2 [Computers and Society]: Social Issues - special needs.

\section{General Terms}

Documentation, Human Factors

\section{Keywords}

Computer documentation, senior citizens, exception-oriented

\section{INTRODUCTION}

One of the most important differences between seniors and others with respect to using a personal computer is that seniors lack a foundation for understanding what the computer really is (from a computer science and information technology perspective), and hence are not really sure what it can (and can't) do for them. Seniors did not grow up using Sony Walkmans or Nintendo Gameboys, and they are often uncomfortable trying new things. They wonder why the computer isn't as simple to operate as their kitchen radio (and rightly so). But of course this is not the case (and maybe never will be).

Most computer documentation is written with many implicit assumptions. Even the popular "Dummies" book series assume some level of background knowledge of consumer electronics that

Permission to make digital or hard copies of all or part of this work for personal or classroom use is granted without fee provided that copies are not made or distributed for profit or commercial advantage and that copies bear this notice and the full citation on the first page. To copy otherwise, or republish, to post on servers or to redistribute to lists, requires prior specific permission and/or a fee.

SIGDOC'03, October 12-15, 2003, San Francisco, California, USA.

Copyright 2003 ACM 1-58113-696-X/03/0010_..\$5.00. many seniors lack [7]. Consequently, instead of reading such forms of documentation, seniors end up calling their grandchildren asking for help in understanding terms like POP3 and URL, which they consider little more than confusing gibberish. They hear their friends say how "easy" it is to do simple things like send email, write and print a letter using Microsoft Word, and browse the Web-and then wonder why they find it so difficult when they try to do it.

During the first half of 2003 a series of free seminars was offered for seniors who were interested in learning more about personal computing. The seminars were loosely structured Question \& Answer (Q\&A) sessions, where participants could ask any question about computers that they wished. The seminars took place in community centers and public libraries in Melbourne, Florida and Montréal, Canada.

Each seminar lasted about two hours, and attracted at least 35 seniors with an interest in personal computing. However, their level of expertise varied considerably, from complete novices who did not yet own a computer, to more advanced users who were already online. There were also some minor differences in the questions raised, due in part to the different geographical locations. For example, many seniors in Florida were interested in learning more about low-cost dialup Internet Service Providers (ISP), perhaps because they are only in Florida for part of the year. In contrast, many seniors in Montréal had broadband connections through Digital Subscriber Lines (DSL), so for them "going online" was a non-issue: they already were online all the time without really knowing it (or caring about how it worked).

Local differences notwithstanding, there were five central themes that arose during all of the Q\&A sessions:

1. How can I do email? (This includes processing attachments.)

2. Which computer should I buy? (How much should I spend?)

3. What is a virus? (How can I protect myself?)

4. Why does the program crash? (What did I do wrong?)

5. Why doesn't the printer work properly?

As a result of these seminars, three key requirements of computer documentation to help senior citizens use personal computers were identified. The next section addresses the first of these requirements: basic vocabulary (the "what"). Section 3 focuses on the second of the requirements: just enough explanation (the "how"). Section 4 describes the third requirement: exceptionoriented guidelines (the "why"). Section 5 summarizes the paper and outlines further work on this topic. 


\section{BASIC VOCABULARY}

From the very beginning of the first seminar it soon became evident that many of the problems experienced by seniors were due to a fundamental lack of understanding of the basic vocabulary of personal computing. Without such an understanding, many seniors have difficulty explaining their problems, and have equal difficultly following written or verbal instructions. For example, at one of the Q\&A sessions, a senior kept saying how he "xed the program", which sounded like "exited" but in reality meant he clicked on the ' $\mathrm{X}$ ' in the top-right to close the window. It took several minutes to clear up this simple misunderstanding, all because he didn't know the proper terminology for closing a window. Before the basic understanding of the computer can be gained, a basic understanding of computer vocabulary must first be achieved. And this means mastering a bewildering array of buzzwords, techno-jargon, and acronyms.

Most personal computers are sold today using what might be called "differentiation through obfuscation." In other words, explaining the attributes of a particular model by throwing a lot of acronyms at the consumer, in the hopes that they will be sufficiently impressed (or overwhelmed) with the quantity of the techno-babble to choose this machine over another one. A quick examination of the glossy advertisements found in the Sunday paper is all that is needed to illustrate this. Terms like GHz, FSB, MB, DDR, SDRAM, GB, ATA, 10/100 NIC, 56K, USB 2.0, 1394 / FireWire, RAID, DVD$\mathrm{RW}$, and so on are used to sway consumers who have very little understanding of any of these things. Without an understanding of the concepts underlying these terms, seniors are left with two main choices: rely on the advice of salespeople, or rely on their own faulty interpretations of these terms to guide them.

The first choice, relying on salespeople, is not always the best option. It is not uncommon to overhear conversations in computer stores between two people, one being the customer and the other the salesperson, which are full of inaccuracies and half-truths - from both parties. For example, no one likes to be told they are spending good money on inferior technology, when for "just a few dollars more" they could have something much better. A good illustration of this is the misinformation surrounding the CPU (Central Processing Unit) for a personal computer. Most of today's computers use a CPU from Intel, with the Pentium 4 or a Celeron chip being the two main choices. It is quite common for a consumer to be told to avoid the Celeron because it is "no good." However, the Celeron is based on the same core as the Pentium 4. For most consumers, there will be very little perceived difference in systems built using the two chips. In fact, most of the differences between the Pentium 4 and the Celeron are not technical: they are primarily due to marketing. Intel was worried about Advanced Micro Devices (AMD) gaining share in the so-called "low end" market, so they created the Celeron as a way of offering an Intel-branded solution for this space as well. The chips are sold differently, but they are manufactured nearly identically. The conversation situation is not necessarily due to any malice on the part of the salesperson. Instead, the problem may just be that they are almost as confused as the customer. And who can blame them?

The second choice, relying on one's own interpretation of unfamiliar computer vocabulary, is not always a good choice either. For example, is a PC with a Pentium $42.2 \mathrm{GHz}$ better than a $\mathrm{PC}$ with an Athlon XP 2400+? How about an iMac with a $1 \mathrm{GHz}$ G4? With little to guide them, most people would base their decision on the size of the number. Assuming they knew that "GHz" means "billions of Hertz," they might say "The 2400+ model must be better, because it is 'bigger' than $2.2 \mathrm{GHz}$, and much bigger than 1GHz." They'd be wrong.

The situation is little better for computing professionals. Consider one of the hottest new developments in information technology: Web services. There is some discussion over exactly what constitutes Web services, but essentially they are networkaccessible interfaces to application functionality. However, if there is one thing about Web services that is unequivocally true, it is acronym rich: .NET, API, ASP, DISCO, EJB, HTTP, IIS, J2EE, NCC, ONE, SOAP, SQL, TCP, UDDI, VBA, WSDL, and XML are just some of the technology monikers that are directly related to Web services. Not only do software engineers need to know the meanings of these acronyms, they need to know how to make proper use of the technologies in order to develop solutions that are reliant on Web services. Without such knowledge, adopting Web services is a very risky proposition [6].

For senior citizens, there is a third and better choice: become an educated user by first becoming familiar with the basic vocabulary of personal computers. In traditional documentation, acronyms and key phrases are usually found in a glossary (and possibly in the index). For seniors learning about computers, the glossary should not an ancillary chapter that is stumbled upon while languidly flipping through the book. Instead, the glossary should be elevated to a first-class chapter, one that is found right at the beginning of the material. Such a glossary would be treated as required reading, not optional information.

However, a glossary in its usual format of phrases and short definitions would not provide enough explanation to truly help senior citizens. The glossary provides the syntax of the personal computer; what is lacking is the semantics - the context in which the phrase is used. This is provided by giving the reader just enough explanation of both the word itself and its role in the functioning of a complete computer system.

\section{JUST ENOUGH EXPLANATION}

The previous section outlined the first requirement of computer documentation for senior citizens: providing the basic vocabulary. The second requirement is to instill just enough (but not too much) understanding of how a personal computer functions so that seniors become educated users. In other words, seniors should know enough about how a computer works "under the hood" to enable them to express their problems and understand the solutions. Creating documentation that imparts just enough understanding is nontrivial. As Walter Mossberg says in his technology column in The Wall Street Journal, “There's no other major item most of us own that is as confusing, unpredictable and unreliable as our personal computers." [4]

Most seniors (like most consumers in general) are blissfully unaware of how a computer works. In an ideal world, they would not need to understand this at all. In the real world, they do-at least a little. This is similar to the level of understanding that most of us have regarding the operation of an automobile. Very few of us are car mechanics, but we have at least a gut-level understanding of how the car works and what is needed to maintain it, to drive it, and so on. The goal is to provide seniors with a rudimentary understanding of what's happening, and at the same time avoid overwhelming them with secondary knowledge that would only serve to further confuse them. 
Determining when this sweet spot of understanding - not too little, not too much - has been reached is not easy. The documentation should provide the aforementioned vocabulary, enough of an overview of the main components of a personal computer, and sufficient examples of common uses of the computer to give the seniors the same gut-level understanding that they have with their cars. Too much information can lead to further confusion, following a cyclical pattern of confusion, understanding, and heightened confusion related to more complex questions.

For example, during the seminars there were many seemingly simple questions asked, such as "Why don't the pictures download?" To properly answer such questions usually required several rounds of clarification, such as "What email program are you using? What ISP are you using? Are you using an anti-virus program?" For most seniors, these questions left then scratching their heads, wondering why they were being asked more questions instead of being given a direct answer. The reason is that there are many ways to interpret the original question; more context was needed to ascertain the true problem. The iterative nature of the Q\&A session actually helped seniors understand many of the issues related to the common problems they encountered. For example, the question related to downloading of pictures led to discussions of email programs, file sizes, attachments, helper applications, and so on. Once the general tenor of the audience switched from scratching heads to nodding heads, the sweet spot had been reached.

The similarity between seniors' knowledge of computers and the general population's knowledge of automobiles offers a potential solution to the documentation challenge of providing just enough understanding: the use of explanation by analogy. Using familiar tasks, languages, and metaphors to introduce new concepts is one of the principals of Carroll's minimalist approach to computer training [3]. It is quite common for people trying to understand something new to first attempt to map the new concept onto one (or more) of the knowledge categories they have created through their life experiences. If a new concept shares enough characteristics with an existing concept that is already well understood, then the new concept can be described according to its similarities and differences with the known entity. In other words, the new concept can be understood by saying "This is just like X, except ..."

The technique of explanation by analogy was used extensively in the Q\&A sessions to instill just enough understanding about many personal computer topics. Invariably, automobiles were used as the basis for comparison. For example, the personal computer industry was described as being similar to the automobile industry at the turn of the twentieth century: an immature industry that produces products prone to breakdown and better suited to the hobbyist than the average consumer.

\section{EXCEPTION-ORIENTED GUIDELINES}

The third requirement of computer documentation for seniors is to provide exception-oriented guidelines for a small set of common tasks. The focus on task exceptions is needed to explain why computers work as they do. Perhaps a better phrase would be "why computers don't work as they are expected to," since computers have a tendency to crash with few clues as to the reason why. Paradoxically, personal computers behave more according to the exception than the rule, so it makes sense to provide documentation that guides the user accordingly.

Exception-oriented guidelines are really just variants on one of the central tenets of Carroll's minimalist approach: task-driven documentation [2]. As a special type of novice user, seniors can also benefit from simplified, task-driven instructions. Seniors are not really interested in learning about everything the computer can do for them. In fact, most seniors have a very small set of core tasks that they are interested in, tasks that are not the same as might be covered by other books or instructional material better suited for a more traditional audience.

Based on the questions posed during the Q\&A sessions, seniors seem to be primarily interested in using their computer in support of family-related activities, such as sending and receiving email, looking (and possibly creating) digital photographs, writing and printing letters, browsing the Web, creating family trees, and playing card games. While these are relatively simple things to do for most people, anyone who has used a computer knows that there are many things that can (and do) go wrong, such as applications freezing for no apparent reason. Therefore, the task-driven documentation needs to be augmented with guidance on what to do when things don't go according to plan.

Such exception-oriented guidelines are very similar to the error recovery principle of Carroll's minimalist documentation theory [1]. In Carroll's view, guided exploration of error possibilities is important to increase the understanding for novice users and decrease the frustration resulting from making so many errors. For example, watching an instructor successfully carry out a computer task, such as saving an email attachment, then going home and failing to replicate the exact same task because of subtle differences in the operating environment (e.g., security settings that might disable access to attachments, unbeknownst to the poor user).

Seniors are similar to Carroll's description of novice users, but there is at least one important difference: unlike self-guided exploratory learners, many seniors seem to prefer structured guidance. Perhaps this characteristic comes from their general inclination to prefer "package tours" rather than "do it yourself" trips. Highly structured vacation packages are extremely popular for seniors' groups, in part because it removes the need to organize the tedious aspects of touring. Choices are made for them - not necessarily the choice they would make by themselves, but a choice nonetheless; the need to make a decision is obviated. This is similar to accepting an application's default settings: they may not be the most personally optimal settings, but they work for most people and will very likely work for this specific user too.

\section{SUMMARY}

This paper outlined three requirements for documentation to help senior citizens learn how to use their personal computers more effectively. These requirements were identified through a series of free seminars conducted in the first half of 2003. Each seminar lasted about two hours and attracted at least 35 participants.

The first documentation requirement is to impart familiarity with a basic vocabulary of computer terms, which can be done using a context-aware glossary. The second requirement is to instill just enough understanding of how a computer works, which can be accomplished using explanation by analogy. The third requirement is to provide seniors with task-driven but exception-oriented instructions, so that they are better prepared to deal with the inevitable problems that will arise.

The findings from the Q\&A sessions outlined in this paper are being used to guide the development of a book on personal computing for senior citizens [5]. There are plans to conduct further 
information seminars in the second half of 2003. Attendees of seminars later in the year may be provided with early drafts of the book's chapters, in the hopes that they can provide constructive feedback on the efficacy of the material.

Senior citizens represent the fastest growing segment of new computer users. The graying of society as a whole is a welldocumented phenomenon, so it should come as no surprise that senior computer users are growing in number and in importance. Seniors have many unique needs related to modern information technology. As such, they offer new challenges to technical writers.

Ultimately, the goal is to end senior citizens' frustration with personal computers. After all, seniors justifiably expect the computer work for them — not the other way around.

\section{REFERENCES}

[1] Barker, T. Writing Software Documentation: A Task-Oriented Approach. Longman, 1998).
[2] Carroll, J. Minimalism Beyond the Nurnberg Funnel. Cambridge, MA: MIT Press, 1998.

[3] Carroll, J. The Nurnberg Funnel. Cambridge, MA: MIT Press, 1999

[4] Mossberg, W. "Mossberg's Mailbox." The Wall Street Journal. Online every Thursday at http://online.wsj.com. Accessed July 2003.

[5] Tilley, S. and Tilley, B. Computing for Wrinklies: A Guide to Personal Computers for the AARP Generation. In progress, 2003.

[6] Tilley, S.; Gerdes, J.; Hamilton, T.; Huang, S.; Müller, H.; Smith, D.; and Wong, K. "On the Business Value and Technical Challenges of Adopting Web Services.” To appear in Journal of Software Maintenance and Evolution: Research and Practice. John Wiley \& Sons, 2003.

[7] Wiley Publishing, Inc. "Dummies.com: The Online Resource for the Rest of Us." Online at http://cda.dummies.com/WileyCDA/. Accessed March 2003 